\title{
Correction to "M-Channel Activation Contributes to the Anticonvulsant Action of the Ketone Body $\beta$-Hydroxybutyrate"
}

\author{
In the above article [Manville RW, Papanikolaou M, and Abbott GW (2020) J Pharmacol \\ Exp Ther, 372(2): 148-156; DOI: https://doi.org/10.1124/jpet.119.263350], the following \\ funding information was omitted by the compositor:
}

This study was supported by the National Institutes of Health National Institute of General Medical Sciences [Grant GM115189] and National Institute of Neurological Disorders and Stroke [Grant NS107671] to GWA.

This information has been added to the HTML and PDF versions of the article.

The compositor regrets this error and any inconvenience it may have caused. 